\title{
Utility of tubular retractors to minimize surgical brain injury in the removal of deep intraparenchymal lesions: a quantitative analysis of FLAIR hyperintensity and apparent diffusion coefficient maps
}

\author{
Evan D. Bander, BA, ${ }^{5}$ Samuel H. Jones, BS, ${ }^{5}$ Ilhami Kovanlikaya, MD, ${ }^{4}$ and \\ Theodore H. Schwartz, MD ${ }^{1-3}$ \\ Departments of ${ }^{1}$ Neurosurgery, ${ }^{2}$ Otolaryngology, ${ }^{3}$ Neuroscience, and ${ }^{4}$ Radiology, ${ }^{5}$ Weill Cornell Medical College, \\ NewYork-Presbyterian Hospital, New York, New York
}

\begin{abstract}
OBJECTIVE Brain retraction systems are frequently required to achieve surgical exposure of deep-seated brain lesions. Spatula-based systems can be associated with injury to the cortex and deep white matter, particularly adjacent to the sharp edges, which can result in uneven pressure on the parenchyma over the course of a long operation. The use of tubular retractor systems has been proposed as a method to overcome these limitations. There have been no studies assessing the degree of brain injury associated with the use of tubular retractors.
\end{abstract}

METHODS Twenty patients were retrospectively identified at Weill Cornell Medical College who underwent resection of deep-seated brain lesions between 2005 and 2014 with the aid of a METRx tubular retractor system. Using the Brainlab software, pre- and postoperative images were analyzed to assess volume, depth, extent of resection, and change in postoperative MR FLAIR hyperintensity and restricted diffusion on diffusion-weighted imaging (DWI).

RESULTS The mean preoperative tumor volume was $16.25 \pm 17.6 \mathrm{~cm}^{3}$. Gross-total resection was achieved in $75 \%$, near-total resection in $10 \%$, and subtotal resection in $15 \%$ of patients. There was a small but not statistically significant increase in average FLAIR hyperintensity volume by $3.25 \pm 10.51 \mathrm{~cm}^{3}(p=0.16)$. The average postoperative volume of DWI high signal area with restricted diffusion on apparent diffusion coefficient maps was $8.35 \pm 3.05 \mathrm{~cm}^{3}$. Assuming that the volume of restricted diffusion on DWI around tumor was 0 preoperatively, this represented a statistically significant increase on DWI $(p<0.001)$.

CONCLUSIONS Although tubular retractors do not appear to significantly increase FLAIR signal in the brain, DWI intensity around the retractors can be identified. These data indicate that although tubular retractors may minimize damage to surrounding tissues, they still cause cytotoxic edema and cellular damage. Objective comparison against other retraction methods, as compared by 3D volumetric analysis or similar methods, will be important in determining the true advantage of tubular retractor systems.

http://thejns.org/doi/abs/10.3171/2015.4.JNS142576

KEY WORDS neurosurgery retractor; tubular; tube; FLAIR; diffusion-weighted imaging; brain injury; magnetic resonance imaging; surgical technique

$\mathrm{B}$ RAIN retraction systems are frequently required to achieve surgical exposure of deep-seated brain lesions. Retraction, however, is associated with complications that include brain edema, vascular compromise causing ischemia, and direct damage to surrounding cortex..$^{27}$ The frequency of retraction-based injury has been estimated to be approximately $10 \%$ in skull base surgery and $5 \%$ in intracranial aneurysm operations. ${ }^{4}$ Techniques such as intermittent retraction, ${ }^{24}$ endonasal trajectories, ${ }^{3,6,10,17}$ and those that use tubular retractors ${ }^{1,2,7,9,11-16,18-23,25}$ have been used to minimize these injuries.

Previously, we reported the successful use of a METRx spinal tubular retractor system, paired with the Brainlab frameless navigation system, for resection of deep-seated intracranial lesions. ${ }^{9}$ The advantages of this tubular retractor system include equal distribution of retraction pressure

ABBREVIATIONS ADC = apparent diffusion coefficient; DWI = diffusion-weighted imaging; GTR = gross-total resection; NTR = near-total resection; STR = subtotal resection.

SUBMITTED November 14, 2014. ACCEPTED April 7, 2015.

INCLUDE WHEN CITING Published online October 2, 2015; DOI: 10.3171/2015.4.JNS142576. 
and gradual dilation of brain tissue to minimize damage to surrounding tissue. Since then, a number of other case reports have described the use of tubular retractor systems in adult and pediatric patients. ${ }^{2,23}$ However, to date, no reports have described the use of $3 \mathrm{D}$ volumetric analysis to determine the effectiveness of these retractor systems in terms of extent of resection and changes in preoperative versus postoperative MR FLAIR signal as well as changes in the diffusion-weighted imaging (DWI) signal. These MR sequences were chosen as correlates of postoperative trauma to surrounding brain with the FLAIR signal as a marker for extracellular fluid and vasogenic edema and restricted diffusion on DWI as a marker for brain cytotoxic edema and ischemic or cell damage. ${ }^{8}$

\section{Methods}

This study was approved by the institutional review board at Weill Cornell Medical College. Twenty patients who underwent resection of deep-seated brain lesions at Weill Cornell Medical College between 2005 and 2014 using a METRx tubular retractor system were retrospectively identified. A retrospective chart review of medical/ surgical oncology, pathology, and radiology records was conducted. Demographic and clinical variables included age, sex, date of surgery, tumor location, retractor size, pathological diagnosis, and volumetric assessment of resection. For comparison with conventional retractors, preoperative MRI scans of all tumors removed prior to the use of tubular retractors were examined to find cases that would have been good candidates for tubular retractors. Assessments were made with the assessor blinded to postoperative FLAIR and DW images. Only a small number of suitable cases were identified $(n=5)$. The surgeon was blinded to postoperative scans and thus was not biased based on estimation of change in FLAIR or DWI. This cohort of patients underwent the same analysis as the tubular retractor patients.

\section{Surgical Technique}

The details of the technique have been presented elsewhere. ${ }^{9}$ In our patient population, a trajectory is planned to target the outer margin of the lesion, either through the crest of a gyrus or the depths of a sulcus, into the capsule of the tumor using 3D navigation planning software (Brainlab). The path is chosen to pass through the least functional white matter tracts based on anatomical information. Diffusion tensor imaging is used as needed based on the presence of adjacent critical white matter tracts, such as motor or visual tracts. A small linear corticectomy is performed, and the white matter is dissected linearly along the lengths of the white matter tracts using the tip of the navigation tool. Then, a custom-built dilator is placed into the barrel of the METRx tube and advanced to the capsule of the lesion with constant irrigation on the pia (Fig. 1). The retractor is attached to the table with a malleable arm and fixed into position. The diameter of the tube is chosen based on the size of the lesion but is generally at least $1 \mathrm{~cm}$ smaller than the maximal diameter of the tumor. The optimal length of the retractor is roughly 2 $\mathrm{cm}$ longer than the distance from the pia to the margin of

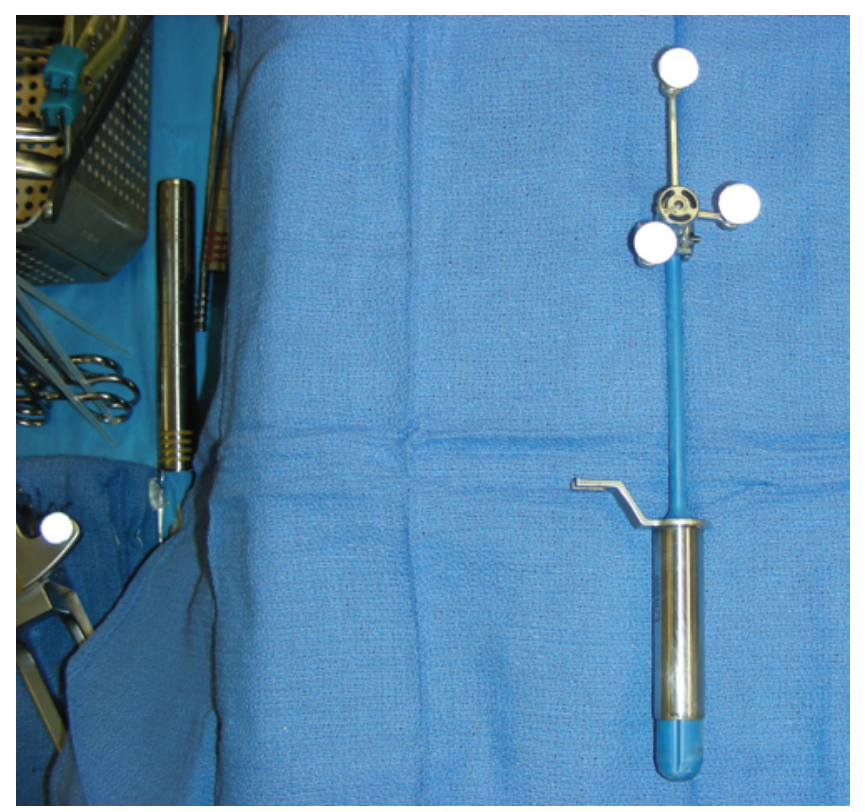

FIG. 1. The custom-built dilating tubular retractor system assembled for insertion with reflecting spheres attached.

the tumor. It is important that the retractor be longer than this distance since the METRx retractor sits $1 \mathrm{~cm}$ above the pial surface and often needs to be advanced deeper into the cavity as the tumor is resected. The retractor arm is frequently moved to ensure that the entire tumor is removed in a systematic fashion. The optimal instruments are similar to those used in endonasal endoscopic skull base surgery, since they are long and thin with the action at the tip and not along the shaft. Either the microscope or the endoscope or a combination can be used depending on the comfort of the surgeon, the diameter of the tube, and the visibility at the tip of the tube.

\section{Volumetric Analysis}

Two individuals conducted the volumetric analysis described below. Neither individual was involved in the surgical or postoperative care of the patients in this study, and both were blinded as to the type of resection completed by the surgical team. Radiographic MRI for each of the identified patients was imported into Brainlab software for volumetric analysis. Preoperative T1-weighted, T1-weighted with gadolinium, and T2-weighted FLAIR scans as well as postoperative T1-weighted, T1-weighted with gadolinium, T2-weighted FLAIR, and DWI scans and apparent diffusion coefficient (ADC) maps were coregistered to align the images. Using the Brainlab software SmartBrush tool, objects were drawn to measure 3D volumes. Tumor burden was defined as enhancement on pre- and postoperative gadolinium T1-weighted images. Hyperintense areas in the vicinity of lesions on T1-weighted images was defined as blood. Using the advanced manipulation tools within the program, blood was subtracted from pre- and postoperative tumor burden for a final tumor volume. Gross-total resection (GTR) was defined as $100 \%$ tumor removal. Near-total resection (NTR) was defined as $>95 \%$, and subtotal resection 
(STR) as $<95 \%$. Brain edema and nonenhancing cellular infiltration around tumors was defined as hyperintensity on pre- and postoperative T2-weighted FLAIR images with the tumor burden subtracted out using the advanced manipulation tool. Change in volume of hyperintensity was determined arithmetically as postoperative edema minus preoperative edema, since shifts in brain anatomy after surgery prevent accurate 3D subtraction within the program. Using the Trajectory Planning tool in Brainlab, oblique images along the plane of the surgical path were created. The depth of tumor was then measured along this surgical plane from the entry point on the skull to the nearest edge of the tumor. DWI was used to determine areas with restricted diffusion (brain ischemia/damage) postoperatively $(n=13)$. The preoperative DWI restricted area was assumed to be 0 since DWI images were not routinely obtained on the navigation scan. Postoperative DW images were analyzed by selecting bright regions with the SmartBrush tool (Fig. 2). However, since a bright signal on T2-weighted imaging can also appear on DWI, the DW images were coregistered and fused with the patient's postoperative ADC map. The areas without low signal intensity on the ADC map were subtracted from the DWI volume so as to select only true regions with restricted diffusion. One patient in our cohort did not have preoperative MR images, and CT scans were used for the volumetric analysis in that case.

\section{Statistical Analysis}

Scatterplots were made comparing the independent variables of preoperative tumor volume, preoperative FLAIR volume, and tumor depth versus the dependent variable of either change in FLAIR or DWI signal. Linear regression trend lines were then fit to these scatterplots. The coefficient of determination $\left(\mathrm{R}^{2}\right)$ was used to determine the fit of this regression and the proportion of variability that could be explained by that model. Paired t-tests were used to compare pre- and postoperative FLAIR hyperintensity and restricted diffusion volume on DWI. Preoperative restricted diffusion on DWI was assumed to be 0 for all cases with postoperative DWI and ADC images. Interobserver variability was determined using the Pearson correlation coefficient, and $\mathrm{p}$ values were reported for each variable. For comparisons between pre- and postoperative volumes, the volumes of the more senior individual were used. A p value $<0.05$ was considered statistically significant. Statistical analysis was performed using Microsoft Excel.

\section{Results \\ Demographics}

Twenty patients (Table 1) with deep-seated brain lesions underwent resection using the METRx tubular dilating retractor system in combination with Brainlab frameless stereotactic navigation. The patients ranged in age from 23 to 81 years. The study population included 9 females and 11 males. The pathological diagnoses included metastatic non-small cell lung carcinoma $(n=5)$, metastatic breast carcinoma $(\mathrm{n}=1)$, meningioma $(\mathrm{n}=2)$, cavernous malformation $(n=1)$, metastatic melanoma $(n=2)$, glioblastoma
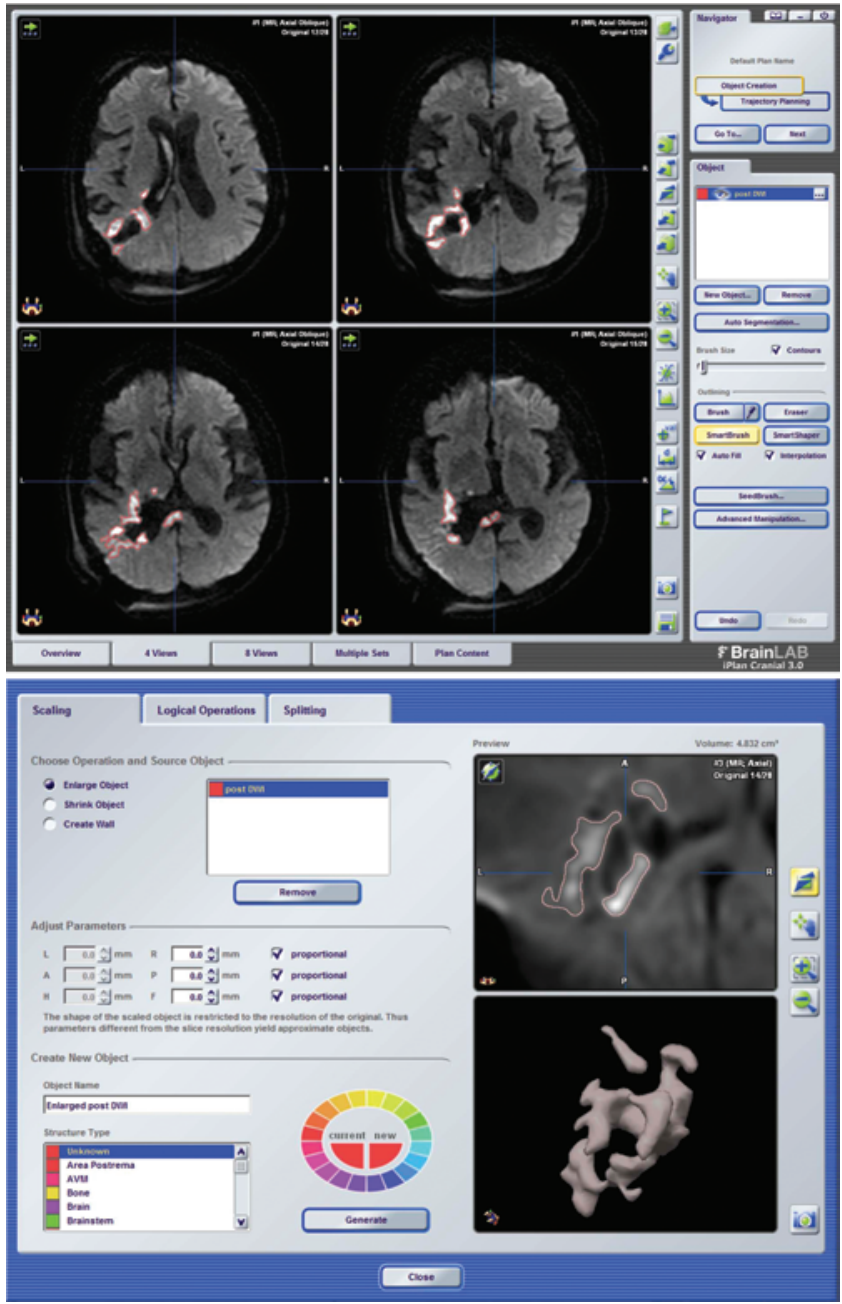

FIG. 2. Brainlab volumetric analysis tools. Upper: SmartBrush selection of DWI signal postoperatively. Lower: 3D reconstruction and volumetric measurement.

$(n=5)$, ependymoma $(n=1)$, granular cell tumor $(n=1)$, toxoplasmosis $(\mathrm{n}=1)$, and craniopharyngioma $(\mathrm{n}=1)$. Tumors were diverse in location, including intraventricular $(n=6)$, frontal $(n=4)$, temporal $(n=4)$, and parietal $(n=5)$ regions. The diameter of the tubular retractor used ranged from 14 to $26 \mathrm{~mm}$, and the length of the retractor ranged from 3 to $7 \mathrm{~cm}$. The frequency of use of each is demonstrated in Fig. 3; operative notes had recorded tubular retractor diameter for 10 patients and the retractor length for 16 patients. The depth of the lesion from the pial surface averaged $45.97 \pm 12.7 \mathrm{~mm}$. Complications occurred postoperatively in 3 of 20 patients and included transient worsening of preoperative aphasia, transient arm pain, and 1 event of asymptomatic cardiac demand ischemia.

\section{Interobserver Reliability}

The Pearson correlation coefficients for the volumetric analysis measurements are reported in Table 2 . The correlation coefficients ranged from 0.82 to 0.997 , demonstrating very strong correlation for all measurements $(\mathrm{p}<$ 0.0001). 
TABLE 1. Demographics

\begin{tabular}{|c|c|}
\hline Variable & Value (\%) \\
\hline \multicolumn{2}{|l|}{ Sex } \\
\hline Female & $9(45)$ \\
\hline Male & $11(55)$ \\
\hline \multicolumn{2}{|l|}{ Age in yrs } \\
\hline Min & 23 \\
\hline Median & 60.5 \\
\hline Mean & 58.35 \\
\hline Max & 81 \\
\hline \multicolumn{2}{|l|}{ Tumor type } \\
\hline Glioblastoma & $5(25)$ \\
\hline Metastatic carcinoma & $6(30)$ \\
\hline Melanoma & $2(10)$ \\
\hline Meningioma & $2(10)$ \\
\hline Other & $5(25)$ \\
\hline \multicolumn{2}{|l|}{ Tumor location } \\
\hline Intraventricular & $6(30)$ \\
\hline Frontal & $4(20)$ \\
\hline Parietal & $5(25)$ \\
\hline Temporal & $4(20)$ \\
\hline Other & $1(5)$ \\
\hline \multicolumn{2}{|l|}{ Retractor diameter in $\mathrm{mm}$} \\
\hline Min & 14 \\
\hline Max & 26 \\
\hline \multicolumn{2}{|l|}{ Retractor length in $\mathrm{cm}$} \\
\hline Min & 3 \\
\hline Max & 7 \\
\hline
\end{tabular}

\section{Illustrative Cases}

Case 1

This 77-year-old woman harbored a left atrial meningioma. The trajectory taken during the surgery can be seen in Fig. 4A and B. The preoperative tumor volume was 19.5 $\mathrm{cm}^{3}$ and the preoperative FLAIR volume was $29.048 \mathrm{~cm}^{3}$. Figure 4C-E shows how the FLAIR signal can initially be selected to include the tumor volume but is subtracted out using advanced manipulations. A GTR was achieved in this patient, as no residual tumor volume could be identified postoperatively. The postoperative FLAIR volume was slightly increased compared with the preoperative FLAIR volume, at a volume of $34.40 \mathrm{~cm}^{3}$, as seen in Fig. 4F.

\section{Case 2}

This 58-year-old man harbored a glioblastoma (Fig. 5). The preoperative tumor volume was $57.53 \mathrm{~cm}^{3}$, and the preoperative FLAIR volume was $27.75 \mathrm{~cm}^{3}$. The postoperative tumor volume was $2.308 \mathrm{~cm}^{3}$, giving an extent of resection of $96 \%$. The postoperative FLAIR volume was not significantly increased at $28.42 \mathrm{~cm}^{3}$. Figure 3C illustrates that the true DWI signal from ischemic tissue is bright on DWI and dark on the ADC map. This DWI hyperintensity tracks along the path of the retractor and has a volume of $8.029 \mathrm{~cm}^{3}$.
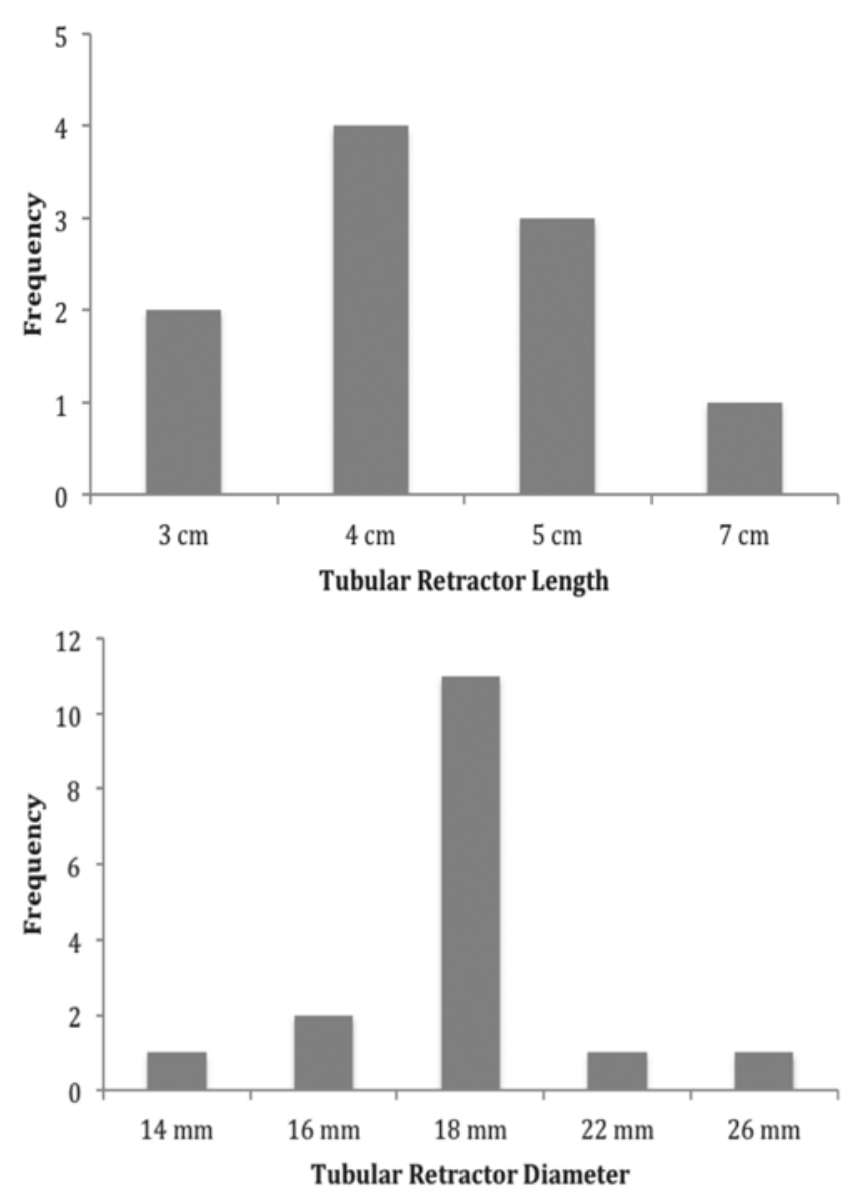

FIG. 3. Bar graph showing the tubular retractor lengths (upper) and diameters (lower) used in the cases. The lengths and diameters were not available for all cases

\section{D Volumetric Analysis}

The average preoperative tumor volume was $16.25 \pm$ $17.6 \mathrm{~cm}^{3}$ (Table 3). Volumes ranged from 0.22 to 61.52 $\mathrm{cm}^{3}$. The average extent of resection was $96.94 \%$. We obtained a GTR in $75 \%$, NTR in $10 \%$, and STR in $15 \%$ of patients.

Volumetric Analysis of Vasogenic Edema (FLAIR Hyperintensity) and Cytotoxic Edema (Restricted Diffusion)

The average preoperative FLAIR hyperintensity was

TABLE 2. Interobserver correlations

\begin{tabular}{ccc}
\hline Variable & r Value & $p$ Value \\
\hline Preop tumor vol & 0.992 & $<0.00001$ \\
\hline Preop FLAIR vol & 0.997 & $<0.00001$ \\
\hline Postop tumor vol & 0.959 & $<0.00001$ \\
\hline Postop FLAIR vol & 0.996 & $<0.00001$ \\
\hline Postop DWI vol & 0.876 & $\mathbf{0 . 0 0 0 0 9}$ \\
\hline$\Delta$ FLAIR vol & 0.821 & $<0.00001$ \\
\hline
\end{tabular}

* Values in boldface are statistically significant. 

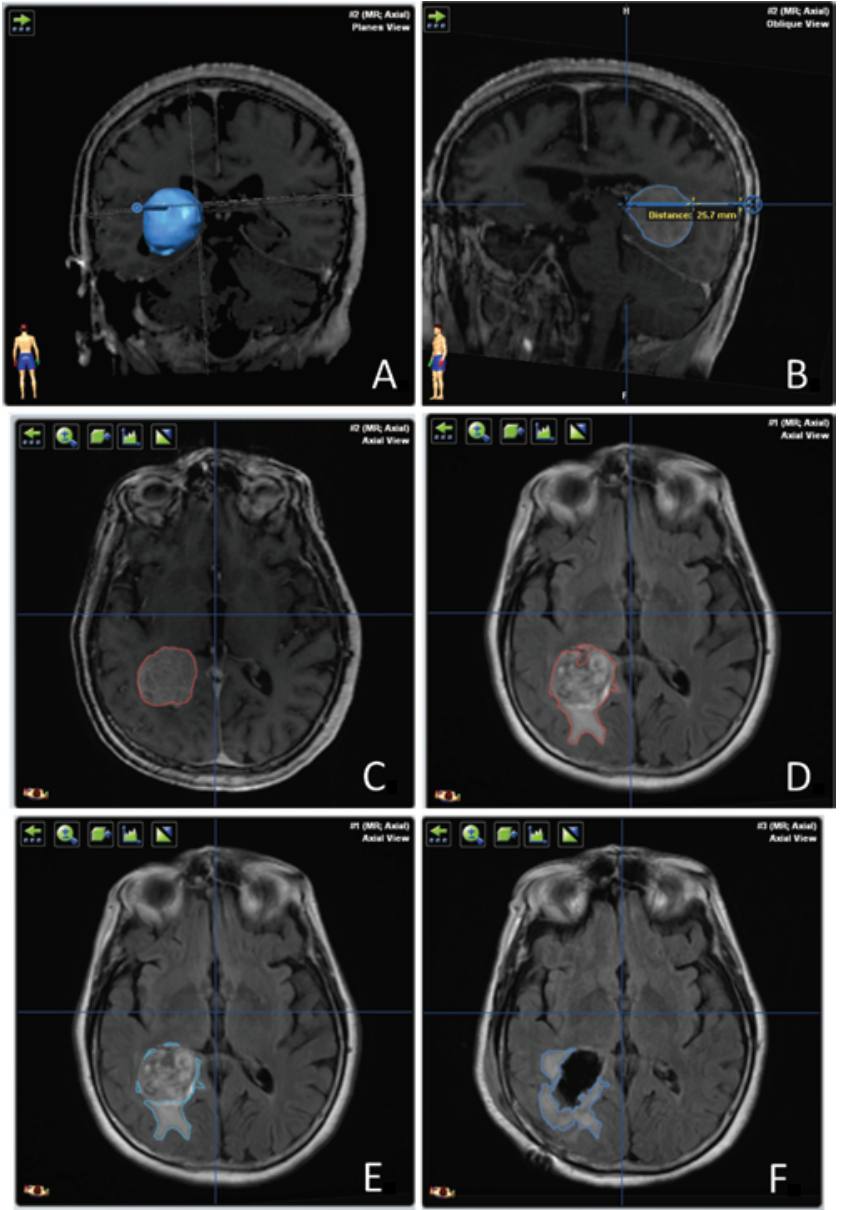

FIG. 4. Case 1. A: Trajectory taken by the surgeon. B: In-plane/ oblique image of the trajectory used for measuring depth of tumor from the pia. C-E: Subtraction of tumor volume from FLAIR. The orange outline is the preoperative tumor volume $(C)$; and the orange outline is the FLAIR volume plus tumor volume (D). E: The preoperative FLAIR volume is calculated by subtracting out the preoperative tumor volume from the FLAIR plus tumor volume by advanced manipulations. F: The postoperative FLAIR volume surrounding the operative cavity.

$41.71 \pm 45.55 \mathrm{~cm}^{3}$. This value ranged substantially from 0 to $157.54 \mathrm{~cm}^{3}$ due to the wide variety of lesions. Postoperatively, the average FLAIR hyperintense signal volume was $43.75 \pm 41.61 \mathrm{~cm}^{3}$. Although there was a small increase in average FLAIR intensity volume by $3.25 \pm$ $10.51 \mathrm{~cm}^{3}$, this was not a statistically significant change in FLAIR volume $(\mathrm{p}=0.16)$. The average postoperative volume of restricted diffusion on DWI was $8.35 \pm 3.05 \mathrm{~cm}^{3}$. Assuming that volume of DWI-restricted diffusion was 0 preoperatively, this represented a statistically significant increase in DWI $(\mathrm{p}<0.001)$.

Linear regression analysis was performed to assess whether the change in FLAIR hyperintensity and volume with restricted diffusion on DWI after surgery correlated with preoperative tumor volume, preoperative FLAIR volume, or depth of tumor. Based on a coefficient of determination $\left(R^{2}\right)$, none of these factors explained a significant amount of variation in the changes in FLAIR or DWI signal after surgery (Table 3).
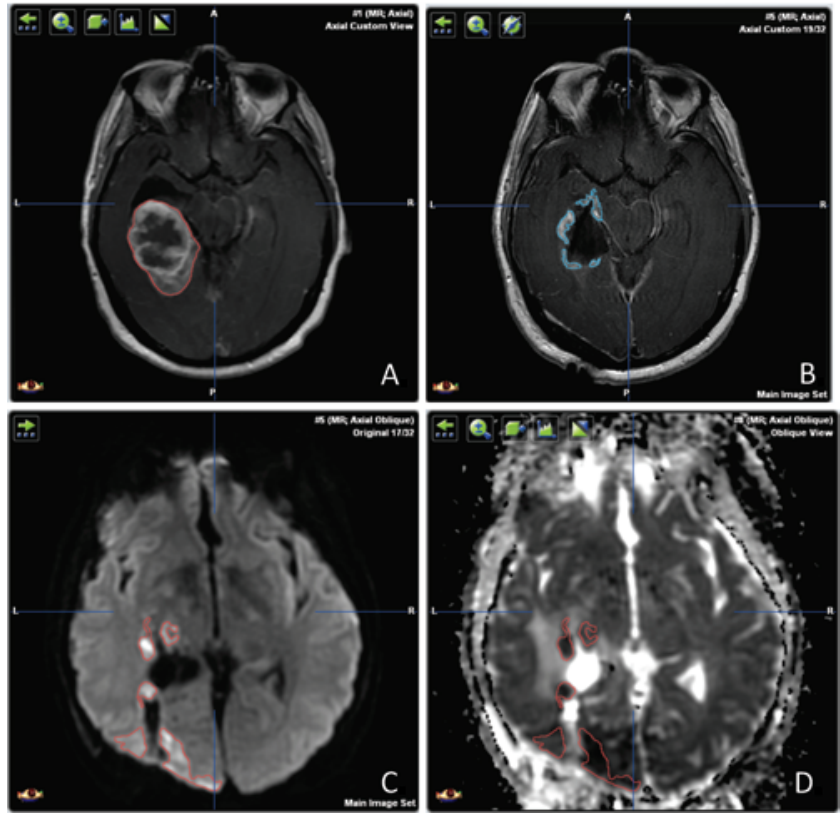

FIG. 5. Case 2. A: The preoperative tumor volume is outlined in orange. B: The postoperative residual tumor is outlined in blue. C and D: DWI hyperintensity postoperatively $(C)$ lines up with the dark area on the ADC map (D).

\section{Comparison With Traditional Retraction}

Five patients were retrospectively identified as harboring deep-seated tumors that would have been suitable for resection using tubular retractors, but they underwent surgery prior to the use of that retraction system (Table 4). Two patients underwent GTR, 2 had NTR, and 1 had an STR. The average preoperative tumor volume in this cohort was $34.46 \pm 14.9 \mathrm{~cm}^{3}$ (Table 5). The average change in FLAIR volume was $2.39 \pm 13.93 \mathrm{~cm}^{3}$, which was not significantly different from the change in FLAIR volume seen in the tubular retractor cohort $(\mathrm{p}=0.9)$. The average postoperative DWI volume was $16.51 \pm 8.9 \mathrm{~cm}^{3}$. This increase in DWI volume showed a trend toward higher DWI volume in the traditional retractor compared with the tubular retractor cohort $(\mathrm{p}=0.16)$; however, it did not reach statistical significance due to the small sample size.

\section{Discussion}

The use of tubular retractors for the resection of intracranial tumors, such as thalamic astrocytomas, was first demonstrated by Kelly and colleagues and expanded upon by Moshel et al. ${ }^{15,16,18}$ Since then, a number of case series/ reports using a variety of retractors and stylets, such as transparent plastic sheaths with metal stylets ${ }^{19}$ or inflatable vinyl retractor tubes ${ }^{12}$ have been reported in the literature. Previously, we reported a series of 10 cases in which an METRx retractor system with frameless stereotactic navigation was safely used for resection of intracranial lesions. Fahim et al. further demonstrated the use of a similar system in a resection of a pediatric arteriovenous malformation. ${ }^{7}$ Almenawer et al. subsequently used a METRx retractor system in a 30-patient cohort. ${ }^{2}$ These additional reports support the feasibility and reproducibility of the technique. 
TABLE 3. Volumetric analysis and $R^{2}$ regression analysis

\begin{tabular}{|c|c|c|c|}
\hline Variable & Value & $\begin{array}{c}\mathrm{R}^{2} \text { vs } \Delta \\
\text { in FLAIR }\end{array}$ & $\begin{array}{l}\mathrm{R}^{2} \text { vs } \Delta \\
\text { in DWl }\end{array}$ \\
\hline Preop tumor vol in $\mathrm{cm}^{3}$ & & 0.003 & 0.016 \\
\hline Min & 0.22 & & \\
\hline Median & 10.69 & & \\
\hline Mean \pm SD & $16.25 \pm 17.61$ & & \\
\hline Max & 61.52 & & \\
\hline Depth of tumor in $\mathrm{mm}$ & & 0.13 & 0.003 \\
\hline Min & 20.80 & & \\
\hline Median & 48.80 & & \\
\hline Mean \pm SD & $45.97 \pm 12.67$ & & \\
\hline Max & 70.10 & & \\
\hline \multicolumn{4}{|l|}{ Extent of resection } \\
\hline Min & $74.93 \%$ & & \\
\hline Median & $100.00 \%$ & & \\
\hline Mean \pm SD & $96.94 \pm 7.16 \%$ & & \\
\hline Max & $100.00 \%$ & & \\
\hline GTR & $15(75 \%)$ & & \\
\hline NTR & $2(10 \%)$ & & \\
\hline STR & $3(15 \%)$ & & \\
\hline Preop FLAIR vol in $\mathrm{cm}^{3}$ & & 0.17 & 0.14 \\
\hline Min & 0.00 & & \\
\hline Median & 25.90 & & \\
\hline Mean \pm SD & $41.71 \pm 45.55$ & & \\
\hline Max & 157.54 & & \\
\hline \multicolumn{4}{|l|}{ Postop FLAIR vol in $\mathrm{cm}^{3}$} \\
\hline Min & 2.90 & & \\
\hline Median & 31.41 & & \\
\hline Mean \pm SD & $43.75 \pm 41.61$ & & \\
\hline Max & 142.54 & & \\
\hline \multicolumn{4}{|l|}{$\Delta$ FLAIR vol in $\mathrm{cm}^{3}$} \\
\hline Min & -17.41 & & \\
\hline Median & 4.39 & & \\
\hline Mean \pm SD & $3.25 \pm 10.51$ & & \\
\hline Max & 30.26 & & \\
\hline \multicolumn{4}{|l|}{ Postop DWI vol in $\mathrm{cm}^{3}$} \\
\hline Min & 2.97 & & \\
\hline Median & 7.92 & & \\
\hline Mean \pm SD & $7.53 \pm 3.13$ & & \\
\hline Max & 14.29 & & \\
\hline
\end{tabular}

The concept underlying the use of tubular retractor systems is that damage to the brain can be reduced by applying an equal distribution of pressure radially around a tube compared with the more concentrated pressure applied on smaller surface areas with older retraction methods. Studies in animals have shown that pressures as low as $25 \mathrm{~mm}$ $\mathrm{Hg}$ can cause electroencephalographic changes ${ }^{5}$ and those as low as $30 \mathrm{~mm} \mathrm{Hg}$ can reduce cerebral blood flow. ${ }^{24}$ Furthermore, with the use of progressive dilation using blunt instruments, there is less transection of white matter tracts.
TABLE 4. Traditional retractor control group

\begin{tabular}{cc}
\hline \multicolumn{1}{c}{ Variable } & Value $^{*}$ \\
\hline Sex & $3(60)$ \\
\hline Female & $2(40)$ \\
\hline Male & 27 \\
\hline Age in yrs & 48 \\
\hline Min & 50.6 \\
\hline Median & 75 \\
\hline Mean & \\
\hline Max & 85.94 \\
\hline Extent of resection & 99.45 \\
\hline Min & $95.55 \pm 6.28$ \\
\hline Median & 100.00 \\
\hline Mean \pm SD & \\
\hline Max & $2(40)$ \\
\hline GTR vs NTR vs STR & $2(40)$ \\
\hline GTR & $1(5)$ \\
\hline NTR &
\end{tabular}

* Values are presented as the number of patients (\%) unless stated otherwise.

Although these theories have been suggested, most studies in humans have been limited to only assessing the feasibility and safety of these retractor systems. Outcomes have by and large been subjective, surgeon-dependent assessments of GTR versus STR, patient length of stay, and occurrence of postoperative complications. Objective methods such as those used in the aforementioned animal studies to assess retraction damage have not been feasible as measures in human populations. This study not only expands on our original case series but represents the first report of the use of 3D volumetric analysis to objectively measure extent of resection as well as quantify cortical damage associated with the use of tubular retractors.

Using Brainlab software, 3D volumetric analysis confirmed that tubular retractors could be successful in achieving GTR of tumors of a variety of pathologies at a variety of depths, locations, and preoperative volumes. Changes in hyperintensity on FLAIR and areas with restricted diffusion on DW images were used to assess postoperative vasogenic edema and cytotoxic edema (ischemia/cellular damage), respectively. Vasogenic edema from trauma results from damage to the blood-brain barrier and causes swelling in the brain with an increase in T2 FLAIR signal that does not show restricted diffusion. ${ }^{26}$ In our data, no statistically significant increase in FLAIR signal occurred after surgery. This suggests that the blood-brain barrier was not significantly damaged and there was not a significant increase in vasogenic edema postoperatively, which supports the concept that tubular retractors are potentially less traumatic than other retraction techniques. However, there are no data available in the literature for other spatula-based techniques for comparison. This study provides a benchmark for comparison.

In spite of the minimal and nonsignificant increase in FLAIR signal, our data showed significant increases in ar- 
TABLE 5. Traditional retractor volumetric analysis

\begin{tabular}{|c|c|}
\hline Variable & Value \\
\hline \multicolumn{2}{|c|}{ Preop tumor vol in $\mathrm{cm}^{3}$} \\
\hline Min & 11.89 \\
\hline Median & 36.42 \\
\hline Mean \pm SD & $34.46 \pm 14.95$ \\
\hline Max & 50.31 \\
\hline \multicolumn{2}{|c|}{ Depth of tumor in mm } \\
\hline Min & 23.40 \\
\hline Median & 36.80 \\
\hline Mean \pm SD & $35.10 \pm 7.93$ \\
\hline Max & 42.30 \\
\hline \multicolumn{2}{|l|}{ Preop FLAIR vol } \\
\hline Min & 21.69 \\
\hline Median & 56.57 \\
\hline Mean \pm SD & $55.33 \pm 28.63$ \\
\hline Max & 98.10 \\
\hline \multicolumn{2}{|c|}{ Postop FLAIR vol in $\mathrm{cm}^{3}$} \\
\hline Min & 28.44 \\
\hline Median & 50.93 \\
\hline Mean \pm SD & $57.71 \pm 25.47$ \\
\hline Max & 93.31 \\
\hline \multicolumn{2}{|c|}{$\Delta$ FLAIR vol in $\mathrm{cm}^{3}$} \\
\hline Min & -18.21 \\
\hline Median & 6.75 \\
\hline Mean \pm SD & $2.39 \pm 13.93$ \\
\hline Max & 15.95 \\
\hline \multicolumn{2}{|c|}{ Postop DWI vol in $\mathrm{cm}^{3}$} \\
\hline Min & 5.71 \\
\hline Median & 16.64 \\
\hline Mean \pm SD & $16.51 \pm 8.89$ \\
\hline Max & 27.07 \\
\hline
\end{tabular}

eas with restricted diffusion on ADC maps after surgery. This signal correlates with cytotoxic edema resulting from ischemic tissue and cell damage. ${ }^{26}$ These results also indicate that FLAIR signal alone may not be an adequate measure of cortical injury after surgery. Although some of the increase in DWI signal occurred around the site of the resected mass, indicating trauma due to surgery and not the retractor, the majority of the signal surrounded the corridor created by the tubular retractor, as seen in $3 \mathrm{D}$ reconstructions of the images (Fig. 2). Since it would be difficult and somewhat subjective to differentiate the 2 causes of injury, we measured them together, which may artificially increase the reported amount of cytotoxic injury caused by the retractor. Nevertheless, this suggests that the tubular retractors, despite the equal distribution of pressure on brain tissue, may cause enough trauma to result in some degree of cytotoxic injury to surrounding white matter.

Comparison with traditional retractors is the next step in understanding the clinical relevance of these findings. Retrospectively, we were able to identify only a small co- hort of patients in our operative caseload who underwent surgery for deep-seated lesions with traditional retractors, but would have been suitable for tubular retractors. Comparing the cohort of tubular retractors to traditional retractors, we found no difference in the change in FLAIR signal but found a nonsignificant trend toward higher DWI volumes in the traditional retractor group. This small control group was not statistically powered to test the hypothesis that tubular retractors cause less damage than traditional retractors; however, it does demonstrate a need for further comparison of surgical retractors by randomized, controlled prospective trials using the quantitative volumetric methods described. Moreover, the increase in cytotoxic edema found around the retractors should serve as an impetus for future biomedical engineering designs to improve this technology. One possible solution might be to develop softer and more flexible tubes that may cause less injury. Another possibility is the dilation method, which could be done in a less traumatic fashion with the aid of an internal expander. Our data suggest that objective tools such as 3D volumetric analysis of DWI may be a useful technique to assess postoperative damage of tubular retractors and can be used in future studies as an outcome measure to compare with other retraction methods.

Since our group has exclusively used tubular retractors since 2005, one limitation of our study was the lack of an adequately powered traditional retractor control group. Another limitation includes the lack of preoperative DW images for comparison. We cannot conclude whether tubular retractors minimize damage compared with other retraction methods; however, we demonstrate evidence that this analysis method can be used to test this hypothesis in future prospective studies.

\section{Conclusions}

We provide objective evidence that the use of tubular retractors to remove deep-seated intraparenchymal tumors does not significantly increase FLAIR signal in the brain, indicating minimal trauma to surrounding white matter. However, increases in DWI signal were identified, demonstrating that cytotoxic injury still occurs around rigid tubular retractor systems. Further refinements and improvements in these systems are needed.

\section{References}

1. Akai T, Shiraga S, Sasagawa Y, Okamoto K, Tachibana O, Lizuka H: Intra-parenchymal tumor biopsy using neuroendoscopy with navigation. Minim Invasive Neurosurg 51:83-86, 2008

2. Almenawer SA, Crevier L, Murty N, Kassam A, Reddy K: Minimal access to deep intracranial lesions using a serial dilatation technique: case-series and review of brain tubular retractor systems. Neurosurg Rev 36:321-330, 2013

3. Anand VK, Schwartz TH: Practical Endoscopic Skull Base Surgery. San Diego: Plural Publishing, 2007

4. Andrews RJ, Bringas JR: A review of brain retraction and recommendations for minimizing intraoperative brain injury. Neurosurgery 33:1052-1064, 1993

5. Bennett MH, Albin MS, Bunegin L, Dujovny M, Hellstrom $\mathrm{H}$, Jannetta PJ: Evoked potential changes during brain retraction in dogs. Stroke 8:487-492, 1977

6. de Divitiis E, Cavallo LM, Cappabianca P, Esposito F: Ex- 
tended endoscopic endonasal transsphenoidal approach for the removal of suprasellar tumors: Part 2. Neurosurgery 60:46-59, 2007

7. Fahim DK, Relyea K, Nayar VV, Fox BD, Whitehead WE, Curry DJ, et al: Transtubular microendoscopic approach for resection of a choroidal arteriovenous malformation. J Neurosurg Pediatr 3:101-104, 2009

8. Greenberg MS: Handbook of Neurosurgery. New York: Thieme, 2010

9. Greenfield JP, Cobb WS, Tsouris AJ, Schwartz TH: Stereotactic minimally invasive tubular retractor system for deep brain lesions. Neurosurgery 63 (4 Suppl 2):334-340, 2008

10. Harris AE, Hadjipanayis CG, Lunsford LD, Lunsford AK, Kassam AB: Microsurgical removal of intraventricular lesions using endoscopic visualization and stereotactic guidance. Neurosurgery 62 (Suppl 2):622-629, 2008

11. Herrera SR, Shin JH, Chan M, Kouloumberis P, Goellner E, Slavin KV: Use of transparent plastic tubular retractor in surgery for deep brain lesions: a case series. Surg Technol Int 19:47-50, 2010

12. Jho HD, Alfieri A: Endoscopic removal of third ventricular tumors: a technical note. Minim Invasive Neurosurg 45:114-119, 2002

13. Jo KI, Chung SB, Jo KW, Kong DS, Seol HJ, Shin HJ: Microsurgical resection of deep-seated lesions using transparent tubular retractor: pediatric case series. Childs Nerv Syst 27:1989-1994, 2011

14. Kassam AB, Engh JA, Mintz AH, Prevedello DM: Completely endoscopic resection of intraparenchymal brain tumors. J Neurosurg 110:116-123, 2009

15. Kelly PJ: Future perspectives in stereotactic neurosurgery: stereotactic microsurgical removal of deep brain tumors. J Neurosurg Sci 33:149-154, 1989

16. Kelly PJ, Goerss SJ, Kall BA: The stereotaxic retractor in computer-assisted stereotaxic microsurgery. Technical note. J Neurosurg 69:301-306, 1988

17. Laufer I, Anand VK, Schwartz TH: Endoscopic, endonasal extended transsphenoidal, transplanum transtuberculum approach for resection of suprasellar lesions. J Neurosurg 106:400-406, 2007

18. Moshel YA, Link MJ, Kelly PJ: Stereotactic volumetric resection of thalamic pilocytic astrocytomas. Neurosurgery 61:66-75, 2007

19. Nishihara T, Nagata K, Tanaka S, Suzuki Y, Izumi M, Mochizuki Y, et al: Newly developed endoscopic instruments for the removal of intracerebral hematoma. Neurocrit Care 2:67-74, 2005

20. Otsuki T, Jokura H, Yoshimoto T: Stereotactic guiding tube for open-system endoscopy: a new approach for the stereotac- tic endoscopic resection of intra-axial brain tumors. Neurosurgery 27:326-330, 1990

21. Patil AA: Stereotactic excision of deep brain lesions using probe guided brain retractor. Acta Neurochir (Wien) 87:150-152, 1987

22. Raza SM, Recinos PF, Avendano J, Adams H, Jallo GI, Quinones-Hinojosa A: Minimally invasive trans-portal resection of deep intracranial lesions. Minim Invasive Neurosurg 54:5-11, 2011

23. Recinos PF, Raza SM, Jallo GI, Recinos VR: Use of a minimally invasive tubular retraction system for deep-seated tumors in pediatric patients. J Neurosurg Pediatr 7:516-521, 2011

24. Rosenørn J, Diemer NH: The influence of intermittent versus continuous brain retractor pressure on regional cerebral blood flow and neuropathology in the rat. Acta Neurochir (Wien) 93:13-17, 1988

25. Ross DA: A simple stereotactic retractor for use with the Leksell stereotactic system. Neurosurgery 32:475-476, 1993

26. Stadnik TW, Demaerel P, Luypaert RR, Chaskis C, Van Rompaey KL, Michotte A, et al: Imaging tutorial: differential diagnosis of bright lesions on diffusion-weighted MR images. Radiographics 23:e7, 2003

27. Zhong J, Dujovny M, Perlin AR, Perez-Arjona E, Park HK, Diaz FG: Brain retraction injury. Neurol Res 25:831-838, 2003

\section{Disclosure}

The authors report no conflict of interest concerning the materials or methods used in this study or the findings specified in this paper.

\section{Author Contributions}

Conception and design: Schwartz, Bander, Kovanlikaya. Acquisition of data: all authors. Analysis and interpretation of data: all authors. Drafting the article: Schwartz, Bander, Kovanlikaya. Critically revising the article: Schwartz, Bander, Kovanlikaya. Reviewed submitted version of manuscript: Schwartz, Bander, Kovanlikaya. Approved the final version of the manuscript on behalf of all authors: Schwartz. Statistical analysis: Schwartz, Bander. Study supervision: Schwartz.

\section{Correspondence}

Theodore H. Schwartz, Department of Neurosurgery, Weill Cornell Medical College, NewYork-Presbyterian Hospital, Box 99, 525 E. 68th St., New York, NY 10065. email: schwarh@med. cornell.edu. 